\title{
PRL-3 increases the aggressive phenotype of prostate cancer cells in vitro and its expression correlates with high-grade prostate tumors in patients
}

\author{
DONNA R. EDWARDS ${ }^{1,2}$, KRZYSZTOF MOROZ $^{3}$, HAITAO ZHANG $^{3}$, DAVID MULHOLLAND $^{2}$, \\ ASIM B. ABDEL-MAGEED ${ }^{4}$ and DEBASIS MONDAL ${ }^{1}$ \\ ${ }^{1}$ Department of Pharmacology, Tulane University School of Medicine, New Orleans, LA 70112; \\ ${ }^{2}$ Tisch Cancer Institute, Icahn School of Medicine at Mount Sinai, New York, NY 10029; Departments of ${ }^{3}$ Pathology \\ and ${ }^{4}$ Urology, Tulane University School of Medicine, New Orleans, LA 70112, USA
}

Received August 25, 2017; Accepted October 31, 2017

DOI: 10.3892/ijo.2017.4208

\begin{abstract}
The increased expression of phosphatase of regenerating liver-3 (PRL-3) has been shown to be associated with the aggressive and metastatic phenotype of different solid tumors. However, it is not known whether PRL-3 plays a similar role in the progression of prostate cancer (PCa). In this study, immunoblot analysis of androgen receptor (AR)-positive $\mathrm{PCa}$ lines (LNCaP and LNCaP-SF) revealed the constitutive cytoplasmic expression of PRL-3, and stimulation with R1881 (AR agonist) rapidly increased the nuclear translocation of PRL-3. The AR-negative cell lines exhibited negligible PRL-3 expression, and the ectopic overexpression of PRL-3 increased both the proliferative and invasive potential of PC3 and DU145 cells. In addition, we measured PRL-3 protein expression in human prostate tumor sections. A high-density prostate tumor microarray (TMA) was immunostained to assess whether PRL-3 expression and its subcellular localization (cytoplasmic and nuclear levels) is associated with the Gleason score (GS), Gleason grade (GG) and tumor stage (T-stage). Digital image analysis (DIA) revealed that PRL-3 expression was significantly higher in the malignant cores, as compared to the non-malignant areas. Increases in both total and nuclear PRL-3 levels were also associated with a higher GS and GG. Metastatic tumors (T4-stage) had lower cytoplasmic, but higher nuclear PRL-3 levels. Furthermore, the nuclear/cytoplasmic ratio for PRL-3 in the tumors graded as GS7 could effectively distinguish between indolent (3+4) and aggressive (4+3) disease. Thus, our experiments using PCa lines suggested that PRL-3
\end{abstract}

Correspondence to: Dr Debasis Mondal, Department of Pharmacology, Tulane University School of Medicine, 1430 Tulane Avenue, New Orleans, LA 70112, USA

E-mail: dmondal@tulane.edu

Key words: prostate cancer, phosphatase of regenerating liver-3, protein pyrosine phosphatase type IVA, member 3, androgen receptor, in vitro, proliferation, invasion, tumor microarray, confocal microscopy, digital pathology, aggressive disease, biomarker is an AR-regulated gene and its androgen-induced nuclear localization may increase the aggressive behavior of PCa cells. Furthermore, the digital analysis of immunostained tumor sections suggested that PRL-3 may be an effective biomarker of high-grade $\mathrm{PCa}$, and its nuclear/cytoplasmic ratio may be used to distinguish between indolent vs. aggressive tumors.

\section{Introduction}

Prostate cancer (PCa) is the most commonly diagnosed cancer in males and the second leading cause of cancer-related mortality in the United States (1). Although the 5-year survival rate for patients with PCa exceeds 95\% for localized tumors, patients with metastatic disease have an overall 5-year survival of $<30 \%$. The measurement of the levels of secreted prostate-specific antigen (PSA) has provided a valuable metric for PCa detection; however, the reliability of PSA as a surrogate biomarker for disease progression has recently been questioned (2). The crucial importance of measuring biomarkers in tumor sections themselves is thus being emphasized, and several of these have progressed into the clinical laboratory (3-5). However, although PCa antigen-3 (PCA3), a long non-coding RNA (lncRNA), is often overexpressed in tumor samples, PCA3 levels alone have failed to distinguish between indolent and aggressive PCa (3). Furthermore, although the transmembrane protease, serine 2 (TMPRSS2)-ETS-related gene (ERG) gene fusion is documented in $40-70 \%$ of patients with $\mathrm{PCa}(4,5)$, both tumor heterogeneity and the lack of knowledge of its functional gene product, render it unlikely that TMPRSS2-ERG screening alone would be sufficient for ascertaining tumor aggressiveness (6). Therefore, there is an urgent need to identify more effective tumor biomarkers whose expression is directly associated with the aggressive and metastatic function of PCa cells.

Phosphatase of regenerating liver-3 [PRL-3; also known as protein pyrosine phosphatase type IVA, member 3 (PTP4A3)] is a protein tyrosine phosphatase frequently upregulated in tumor cells undergoing epithelial to mesenchymal transition (EMT) and in those with increased proliferative and metastatic ability $(7,8)$. The unique $\mathrm{COOH}$-terminal prenylation motif of PRL-3 determines the function of this protein and its location within the cell. 
Several studies have also demonstrated that PRL-3 regulates the function of p53, a crucial tumor suppressor protein that dictates cell cycle progression, genomic stability and apoptosis (9-11). However, although the increased PRL-3 expression, both at the mRNA and protein level, has been reported in several solid tumors, including breast and colorectal carcinomas $(12,13)$, its potential as a reliable biomarker of aggressive PCa and its ability to predict disease progression has not yet been thoroughly investigated, at least to the best of our knowledge.

In the present study, by using a high-density $\mathrm{PCa}$ tumor microarray (TMA) and computer-aided image analysis software (Image $\mathrm{JM}^{\mathrm{TM}}$ ) we measured the PRL-3 protein levels in tumor sections stratified according to the Gleason score (GS), Gleason grade (GG) and tumor stage (T-stage). We aimed to determine whether the total and subcellular levels of PRL-3 may be used to predict the aggressive phenotype of prostate tumors. In addition, in vitro experiments were carried out using $\mathrm{PCa}$ cell lines to investigate the function of PRL-3 in PCa cells, under both basal and androgen-stimulated conditions. Exposure to the androgen agonist (R1881) increased the nuclear localization of PRL-3. The overexpression of PRL-3 increased both the proliferative and invasive potential of PCa cells. Our novel findings indicate that PRL-3 is an effective biomarker of high-grade $\mathrm{PCa}$ and its nuclear/cytoplasmic ratio may be used to distinguish between indolent vs. aggressive tumors.

\section{Materials and methods}

Reagents. Cell culture media and antibiotics were purchased from CellGro (Manassas, VA, USA). Fetal bovine serum (FBS) was obtained from Atlanta Biologicals (Lawrenceville, GA, USA) and charcoal-stripped FBS (CS-FBS) was from Invitrogen (Carlsbad, CA, USA). The synthetic androgen, R1881, was purchased from Sigma-Aldrich (St. Louis, MO, USA). The subcellular fractionation kit was from Thermo Scientific (Rockford, IL, USA). Primary antibody against AR (cat. no. 06680) was from Millipore (Billerica, MA, USA) and antibody against PRL-3 (cat. no. ab50276) was from Abcam (Cambridge, MA, USA). The secondary antibody, TX-Red conjugated goat anti-rabbit IgG (cat. no. T-2767) was from Life Technologies (Carlsbad, CA, USA). Vectashield ${ }^{\mathrm{TM}}$ mounting medium containing DAPI was purchased from Vector Laboratories (Burlingame, CA, USA). The PRL-3 expression plasmid (pMLV-PRL-3) and the empty vector (pBabe-puro) were kind gifts from Dr Y. Jiang (14). Transient transfection was performed using a Lipofectamine LTX Plus kit from Invitrogen, and carried out according to manufacturer's instructions. Vector-transfected cells were harvested $24 \mathrm{~h}$ post-transfection and used in proliferation, migration and invasion assays.

Oncomine database analysis. Oncomine is a web-based datamining platform (http://www.oncomine.org). Oncomine's gene search function was used to locate microarray studies for which gene expression data were publicly available. $P R L-3$ (also known as $P T P 4 A 3$ ) gene expression was queried between normal gland and prostate adenocarcinoma. Data from large-scale microarray studies were processed by Oncomine and results obtained were presented in box plots, along with $\mathrm{P}$-values, fold change and gene rank. Query results from multiple studies showed significant increases in $P R L-3$ gene expression in prostate adenocarcinomas.
Tumor microarray. A high-density PCa TMA (cat. no. PR2085B) from BioMax ${ }^{\mathrm{TM}}$ (Rockville, MD, USA) containing 208 tumor cores from 114 patients was used for our immunostaining and digital image analysis (DIA). These 114 tissue cores included 8 normal samples and 106 tumor samples, which were represented by 2 transitional cell carcinomas, 12 tumor-adjacent normal tissue samples and 92 prostate adenocarcinomas. Furthermore, these 106 tumor samples consisted of 15 non-malignant cores and 91 malignant cores. In the TMA, the prostate tumor cores were also stratified by their pathological landscapes, i.e., GS, GG and T-stage.

Cell culture. The LNCaP, PC3, DU-145 and CWR22Rv1 cells were purchased from the American Type Culture Collection (ATCC, Rockville, MD, USA). The LNCaP-SF cell line was generated in Dr Iwasa's laboratory (15) and the LAPC4 cell line was developed in Dr van Bokhoven's laboratory (16). All PCa cell lines were maintained in RPMI-1640 medium containing antibiotics (penicillin/streptomycin) and supplemented with $10 \% \mathrm{FBS}$. The cells were grown at $37^{\circ} \mathrm{C}$ in a humidified incubator containing $5 \% \mathrm{CO}_{2}$. In specific experiments, to mimic steroid hormone deprived conditions, experiments were carried out in media supplemented with $10 \%$ CS-FBS. The cells were cultured at $37^{\circ} \mathrm{C}$ in a humidified incubator containing $5 \% \mathrm{CO}_{2}$.

Cell proliferation assay. MTT assays were performed to determine cell proliferation in both the control vector- and PRL-3 vector-transduced cells. Briefly, the cells were seeded in a 96 -well plate $\left(5 \times 10^{3} /\right.$ well) and proliferation was measured at 24-72 h. At the indicated time points, MTT dye (20 $\mu$ l) (SigmaAldrich) was added to each well and incubation was carried out for 3-4 h at $37^{\circ} \mathrm{C}$. The formazan crystals were solubilized in DMSO and optical density (OD) was measured at $540 \mathrm{~nm}$ using a $\mu$ Quant spectrophotometric plate reader from Bio-Tek (Seattle, WA, USA). Differences in cell proliferation between the empty vector-transduced (control) and $P R L-3$ transduced cells (experimental) are expressed as a percentage of the control.

Invasion assay. Boyden chambers were used to measure the effect of PRL-3 overexpression on PCa cell invasion through Matrigel coated inserts ( $8-\mu \mathrm{m}$ pore). Matrigel (cat. no. 356230) was purchased from BD Biosciences (San Jose, CA, USA). Both the control and treated cells were suspended in medium containing $1 \%$ FBS and added to the upper compartment, and medium containing $10 \%$ FBS was added to the lower chamber. The cells $\left(2 \times 10^{5}\right)$ were placed on inserts coated with $30 \mu 1$ Matrigel and invasion was measured after $20 \mathrm{~h}$ of incubation at $37^{\circ} \mathrm{C}$. Filters were fixed with methanol for $30 \mathrm{~min}$ and then stained with $0.2 \%$ crystal violet in $20 \%$ methanol for a further $30 \mathrm{~min}$. The inserts were washed 4 times with distilled water, dried overnight, cells counted in 5 fields, and representative images were captured. Cells were counted at x10 magnification using an Olympus IX71 microscope with a DP71 digital camera (Olympus, Tokyo, Japan).

Migration assay. Wound healing assays were carried out to examine the effects of PRL-3 overexpression on the migratory phenotype of PCa cells. Briefly, the cells were grown in 6-well Petri-plates to $80-90 \%$ confluency, and a 1-ml pipette tip was used to scratch the cell monolayer. At different time 


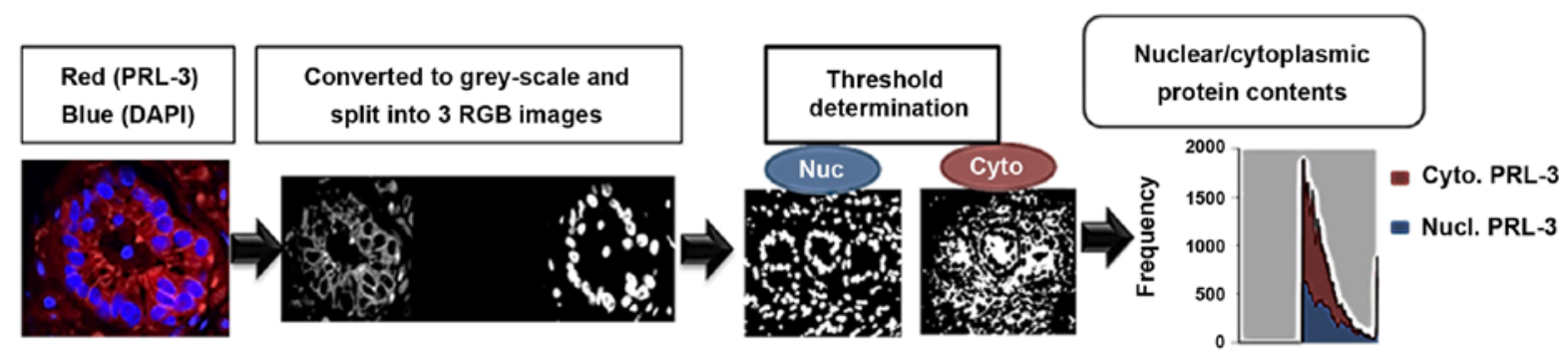

Figure 1. A schematic for image acquisition and analysis. Both total and nuclear phosphatase of regenerating liver-3 (PRL-3) levels were measured in immunostained tumor cores. Images were captured using a confocal microscope (x60 magnification). Both DAPI (nuclei) and TX-Red (PRL-3) staining was viewed simultaneously. Digital quantification of PRL-3 staining intensity and its subcellular localization (cytoplasm vs. nuclear) were measured using the ImageJ software (NIH). Original IFM images were converted into binary masks. Two binary overlay images, representing cytoplasmic and nuclear staining, were acquired and were applied to the original PRL-3 stained images. In each core, the integrative density values (IDV) for nuclear staining intensities were divided by cytoplasmic staining to obtain the nuclear/cytoplasmic ratios.

points (24-72 h) images of the wound were captured using a Olympus IX71 microscope with a DP71 digital camera. Wound widths were calculated by measuring the distance between 4-5 random points within the wound edges. Changes in wound widths were calculated by dividing the average wound widths observed at 12,24 and $48 \mathrm{~h}$ by the average initial wound widths at the 0 -h time point.

Immunoblot analysis. The cells were seeded in 10-cm dishes and grown until 80-90\% confluent. For androgen stimulation experiments, the cells were rinsed with $1 \mathrm{X}$ PBS, the medium was replaced with phenol-red free RPMI-1640 with $10 \%$ CS-FBS for $24 \mathrm{~h}$, following which the cells were treated with the AR-agonist, R1881 (1 nM) for 2-48 h. Cytoplasmic and nuclear extracts were obtained using a subcellular fractionation kit (cat. no. 78840; Thermo Scientific). Cell lysates were electrophoresed using 4-20\% Tris/glycine SDS-PAGE gels. Resolved proteins were then transferred onto PVDF membranes (Millipore) and non-specific binding blocked with $3 \%$ BSA in 1X TBST. The blots were incubated overnight at $4{ }^{\circ} \mathrm{C}$ with 1:500 dilutions of the primary antibodies against either AR or PRL-3. Subsequently, the blots were washed and incubated with the secondary antibody for $1 \mathrm{~h}$. Blots were developed using enzyme chemiluminescence (ECL) and visualized with a Fujifilm LAS-400 Luminescence Imager.

Immunostaining. The TMA sections first underwent heatantigen retrieval using Borg decloaker buffer (cat. no. BD100) from Biocare Medical (Concord, CA, USA). Subsequently, the sections were dehydrated with xylene and then rehydrated by sequential incubation with 100, 95 and $70 \%$ ethanol, and then washed with PBS. The samples were rinsed with $0.05 \%$ saponin in PBS. Cell permeabilization was carried out by incubating the slides in $100 \%$ methanol at $-20^{\circ} \mathrm{C}$ for $10 \mathrm{~min}$. The sections were then rinsed with $0.05 \%$ saponin washing buffer and blocked with normal goat serum containing blocking buffer (cat. no. PCN500; Life Technologies). The sections were then incubated with the primary antibody at $4^{\circ} \mathrm{C}$ overnight and then incubated with the secondary antibody for $1 \mathrm{~h}$ at room temperature and then treated with the Vectashield mounting medium.

Image acquisition and analysis. A schematic for image acquisition and analysis is provided in Fig. 1. Briefly, immu- nostained images were captured using a Nikon A1 Confocal Microscope (Nikon, Melville, NY, USA) and visualized under x60 magnification under oil immersion. An A1 Airy pinhole with a Galvano scanner and 2 frames averaging was used to capture all images in z-field planes and an auto-gain filter calibration was used to process the sub-saturated images. For each core, 5 regions of interest (ROI) were selected to represent the tumor pattern. Both DAPI (nuclei) and TX-Red (PRL-3) staining were viewed simultaneously.

Digital quantification of PRL-3 staining intensity and its subcellular localization (cytoplasm vs. nuclear) were determined by using ImageJ software with a ND2 Reader plug-in (NIH, Bethesda, MD, USA), as previously described (17). Briefly, images were analyzed in split channels for DAPI and TX-Red, and a median filter was applied ( $3 \times 3$ pixels radius) to control for the background. Original images were converted into binary masks, based on image thresholds. The binary image of DAPI staining was subtracted from the TX-Red binary image using the ImageJ image calculator. Subsequently, two binary overlay images, representing 'true' cytoplasmic and nuclear staining, were acquired and applied to the original PRL-3-stained images to normalize the background. Five different ROIs were assessed for their integrative density values (IDV). In each core, total PRL-3 was quantified by taking the total TX-Red IDV divided by the total DAPI IDV. In addition, to determine its subcellular levels, nuclear staining intensity IDVs were divided by the IDV of cytoplasmic staining, which provided a nuclear/ cytoplasmic (Nuc:Cyto) ratio (Fig. 1).

Ki67 staining. Ki67 staining of the tumor sections was carried out to determine the proliferative index of ROIs. Briefly, the slides were incubated for $1 \mathrm{~h}$ with blocking buffer in normal goat serum (5\% goat serum, $0.3 \%$ Triton X-100 in PBS) and $\mathrm{MOM}^{\mathrm{TM}}$ solution from Vector Laboratories. The slides were then incubated overnight at $4^{\circ} \mathrm{C}$ with a 1:500 dilution of Ki67 antibody (cat. no. sc-23900; Santa Cruz Biotechnology, Inc., Santa Cruz, CA, USA). Subsequently, the slides were incubated for 45 min with 1:500 dilution of the biotin-conjugated secondary antibody (cat. no. BP-9200; Vector Laboratories), washed and then incubated with horseradish peroxidase (HRP)-conjugated streptavidin (Vector Laboratories) for $25 \mathrm{~min}$. The slides were then incubated with diamino benzidine (DAB; Vector Laboratories) and images captured. Images 
A Liu et al. (2006)

Gene rank: 211 (in top $2 \%$ )

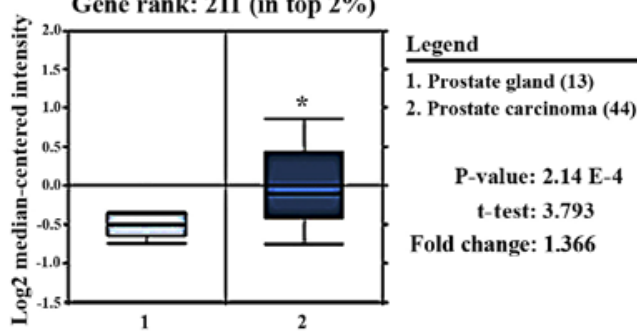

C Taylor et al. (2010)

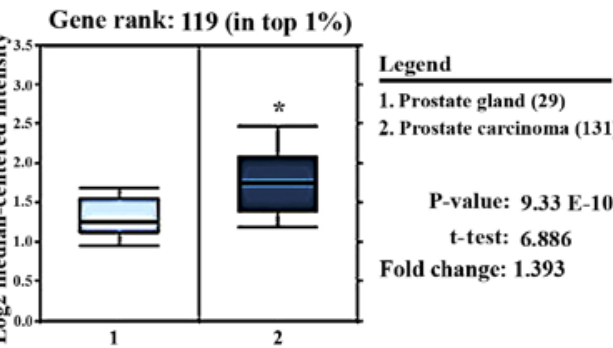

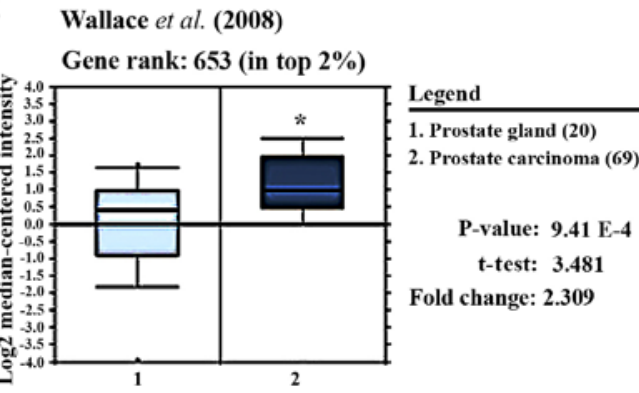

D

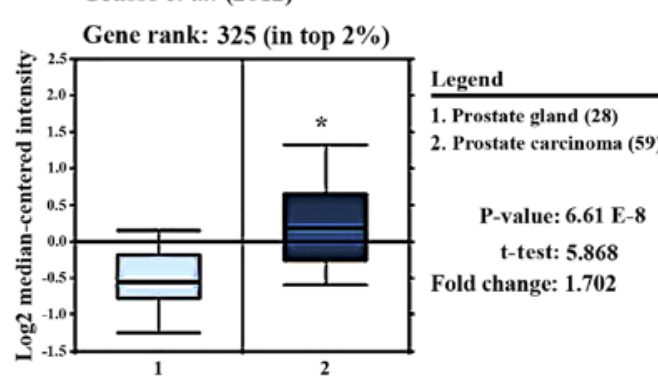

Figure 2. Oncomine-based microarray database query of phosphatase of regenerating liver-3 (PRL-3) gene expression. Four different reports were queried: (A) Liu et al (21); (B) Wallace et al (22); (C) Taylor et al (23) and (D) Grasso et al (24). Studies compared normal PRL-3 mRNA levels in prostate gland and prostate adenocarcinoma. The overexpression gene rank for PRL-3 is provided at the top of the box-and-whisker plots. Number of samples used in each study is provided in parenthesis. Statistical analysis, fold changes and P-values were obtained in the Oncomine query. $P R L-3$ gene was overexpressed in prostate adenocarcinomas.

were captured using a Nikon Eclipse $\mathrm{Ci}$ microscope with a DS-U3 digital camera (Nikon, Tokyo, Japan).

Statistical analysis. All measurement data were exported to an Excel spreadsheet for further statistical analysis, as previously described $(18,19)$. Groups containing $<4$ representations $(n<4)$ were not considered for statistical analysis. The IDV values were averaged for each core and were grouped according to the GS, GG and primary T-stage. Groups, where continuous variables did not follow a normal distribution curve, were assessed using the non-parametric rank testing. The Mann-Whitney U test was used to compare staining differences between the malignant and non-malignant cores. The Kruskal-Wallis $\mathrm{H}$ test was used to compare PRL-3 staining intensities among different GS and T-stage. Analyses were performed using GraphPad Prism and SPSS statistical software packages.

\section{Results}

PRL-3 gene is overexpressed in prostate adenocarcinomas. To determine whether $P R L-3$ gene expression is associated with aggressive prostate tumors, we carried out an Oncomine ${ }^{\mathrm{TM}}$ based database query (20). The analysis of the data from 4 previous reports is shown in Fig. 2. Liu et al was the first to clearly document $(\mathrm{P}<0.0001)$ that $P R L-3$ gene expression was markedly higher in tumor cores than in normal stromal areas (Fig. 2A) (21). In a later study, in which samples were analyzed on an Affymetrix microarray, Wallace et al demonstrated $(\mathrm{P}<0.0001)$ a $>2$-fold higher $P R L-3$ expression in tumor samples vs. normal stromal areas (Fig. 2B) (22). By comparing a large number of prostate carcinoma and normal adjacent prostate tissue specimens, Taylor et al also showed that PRL-3 was amongst the top $1 \%$ of genes upregulated in prostate tumor cells ( $\mathrm{t}=6.89, \mathrm{P}<0.0001)$ (Fig. 2C) (23). In a more recent study, $P R L-3$ expression was measured in both castrate-resistant metastatic PCa and localized prostate carcinoma, and compared with benign prostate tissue specimens (Fig. 2D). Grasso et al clearly demonstrated that PRL-3 mRNA levels were 1.7-fold higher in tumors vs. normal cores and ranked amongst the top $2 \%$ of overexpressed genes in tumor cells $(\mathrm{t}=5.9, \mathrm{P}<0.0001)(24)$. Therefore, $P R L-3$ gene expression is strongly associated with prostate adenocarcinoma and is amongst the top 1-3\% of overexpressed genes. However, little is known about the expression of PRL-3 protein in prostate tumors.

PRL-3 protein levels correlate with aggressive prostate tumors. Using a validated PRL-3 antibody, we first quantified PRL-3 staining intensity in both stromal areas and tumor nodes. Confocal immunofluorescence microscopy was used to examine the PRL-3 protein levels in PCa using a TMA containing prostate tumor cores stratified by GS, GG and tumor, node and metastasis (TNM) staging. The results obtained with the GS and GG stratification are discussed herein (Fig. 3) and those correlating with TNM classifications are presented later (Fig. 6). As compared to areas containing normal glands (control), PRL-3specific staining was increased in aggressive tumor cores (GS6, GS7 and GS8) (Fig. 3A). In the tumor cores graded as GS6 and GS7, PRL-3 overexpression was primarily observed in the cytoplasm, and the GS8-graded cores exhibited diffuse staining with both nuclear and cytoplasmic PRL-3 detection (Fig. 3A). Furthermore, as compared to the non-malignant cores $(n=15)$, PRL-3 expression was significantly higher in the malignant tissues $(n=91)(\mathrm{U}=212, \mathrm{P}<0.0001)$ (Fig. 3B). Of note, although total PRL-3 expression was not directly associated with a lower GS, several of the higher pathological cores exhibited a clearly elevated PRL-3 expression (Fig. 3C and Table I). In all malignant 
A
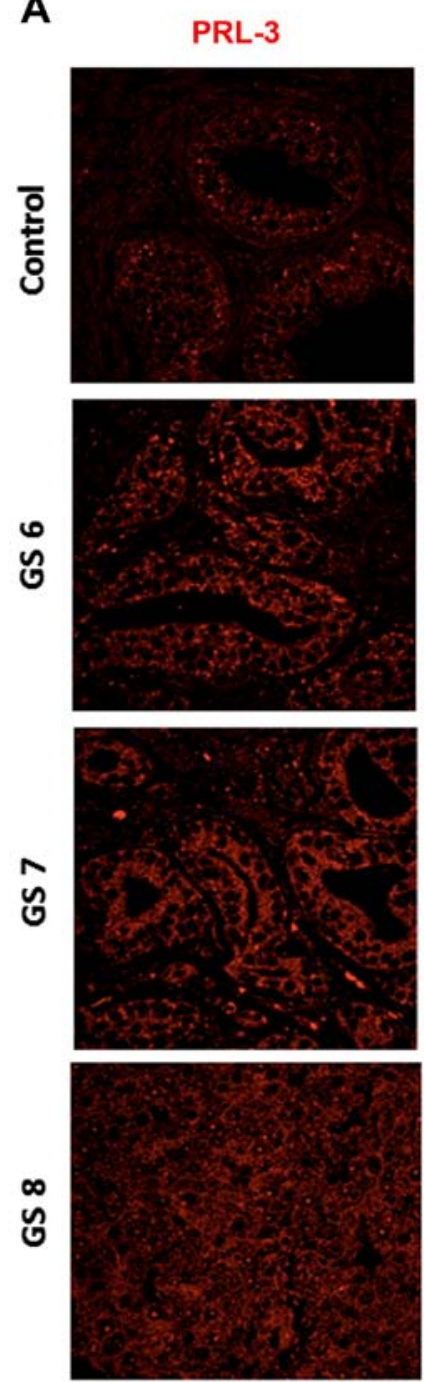

PRL-3, DAPI
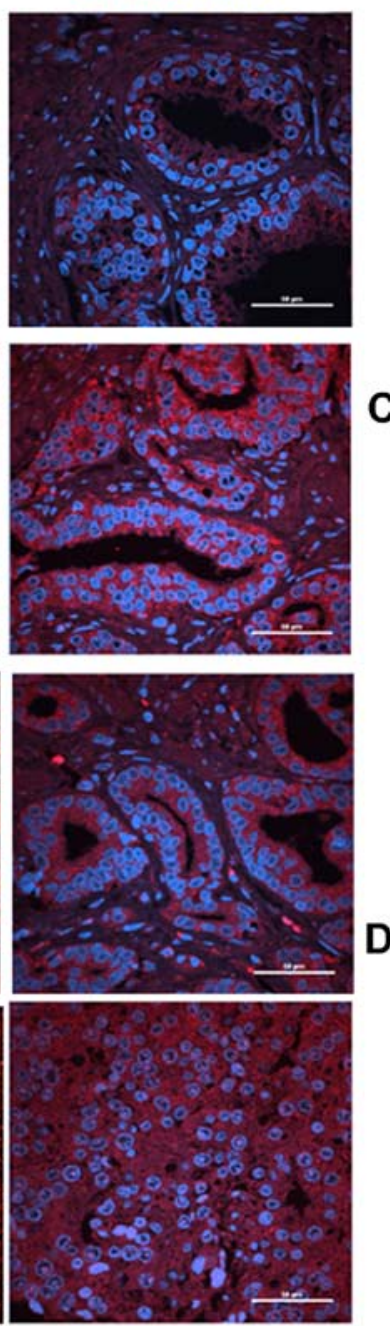

B

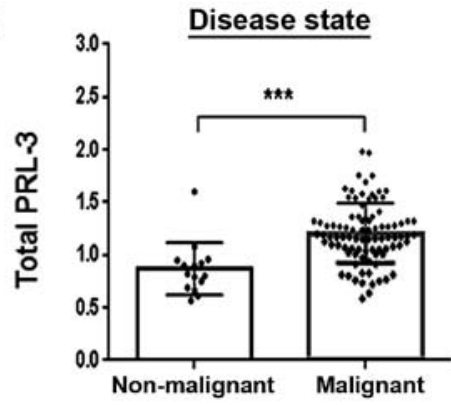

C

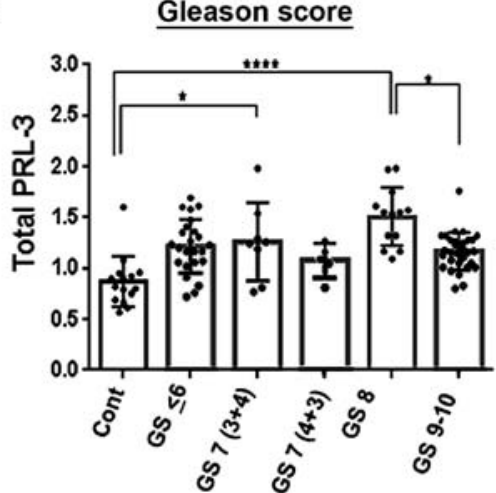

D

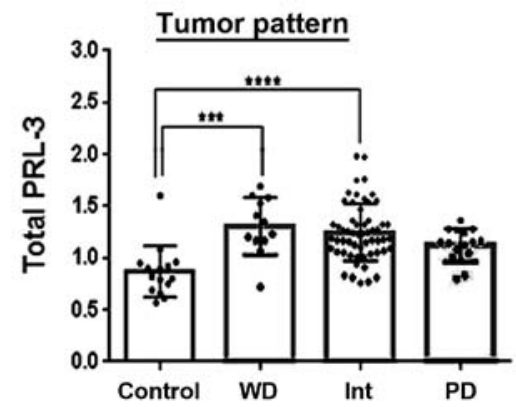

Figure 3. Digital analysis of phosphatase of regenerating liver-3 (PRL-3) protein levels in TMA cores. (A) Immunofluorescence microscopy of total PRL-3 in prostatic adenocarcinomas (scale bar, $50 \mu \mathrm{m}$ ). (B) Increase in total PRL-3 expression was associated with malignant cores. (C) Increased total PRL-3 was associated with high GS tumors. (D) Total PRL-3 expression was associated with histologically well-differentiated (WD) and intermediate (int) tumor patterns, but not with control (cont) or poorly-differentiated (PD) tumor cores. Error bars represent interquartile ranges, $\mathrm{a}=0.05\left({ }^{*} \mathrm{P}<0.05 ;{ }^{* * *} \mathrm{P}<0.01 ;{ }^{* * * *} \mathrm{P}<0.001 ;\right.$ and $\left.{ }^{* * * * *} \mathrm{P}<0.0001\right)$. PRL-3 protein was overexpressed in prostate tumor cores.

tissues, the mean rank analysis demonstrated a 2.65-fold increase in total PRL-3 expression, and the highest increase was observed in GS8 cores $(\mathrm{P}<0.0001)$. Furthermore, although both the GS9and GS10-graded cores exhibited a higher PRL-3 expression compared to the non-malignant cores, these aggressive tumor cores consistently exhibited lower total PRL-3 levels than the GS8 cores $(\mathrm{P}<0.05)$. The upregulation of total PRL-3 expression also correlated well with increasing GG tumor cores. This was evident in both GG2- and GG3-graded cores $(\mathrm{P}<0.001)$ and particularly in the GG4 cores $(\mathrm{P}<0.0001)$ (Fig. 3D and Table I). Importantly, although the GS7 cores exhibited slight increases in total PRL-3 expression (primarily cytoplasmic staining) this increase was mostly associated with the less aggressive GS7 (3+4) cores $(\mathrm{P}<0.05)$, but not with the more aggressive GS7 $(4+3)$ cores, which showed evidence of nuclear PRL-3 staining.

PRL-3 expression correlates with the aggressive function of PCa cell lines. A functional role for nuclear PRL-3 has been implicated in previous studies $(25,26)$. Thus, in this study, to further corroborate our observations on PRL-3 overexpression in clinical samples, we carried out in vitro experiments to examine PRL-3 expression and function in different $\mathrm{PCa}$ cell lines (Fig. 4). Immunoblot analysis documented both the PRL-3 and androgen receptor (AR) protein levels in the androgen-dependent cell line, $\mathrm{LNCaP}$, as well as in four castration resistant PCa (CRPC) cell lines, which consisted of both AR-positive CRPC lines (i.e., CWR22Rv1 and LAPC4) and AR-negative CRPC lines (i.e., PC3 and DU145) (Fig. 4A). Of note, the expression of PRL-3 directly correlated with the AR expression status of the PCa cell lines, LNCaP, 22Rv1 and LAPC4. Negligible PRL3 expression was observed in the AR-negative PC3 and DU145 cells (Fig. 4A). We then examined whether androgen (R1881) stimulation alters PRL3 levels in PCa cells. In the LNCaP cells, both AR and PRL-3 were sequestered in the cytosolic fraction (Fig. 4B, top panel) and stimulation with the AR agonist, R1881 ( $1 \mathrm{nM})$, caused a rapid increase in nuclear AR levels within $2 \mathrm{~h}$ post-stimulation. Of note, R1881 stimulation similarly increased the nuclear levels of 
A

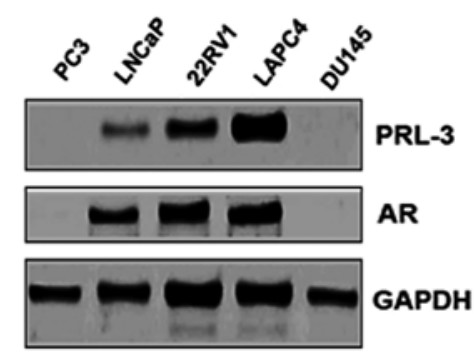

B LNCaP

(hormone-dependent)

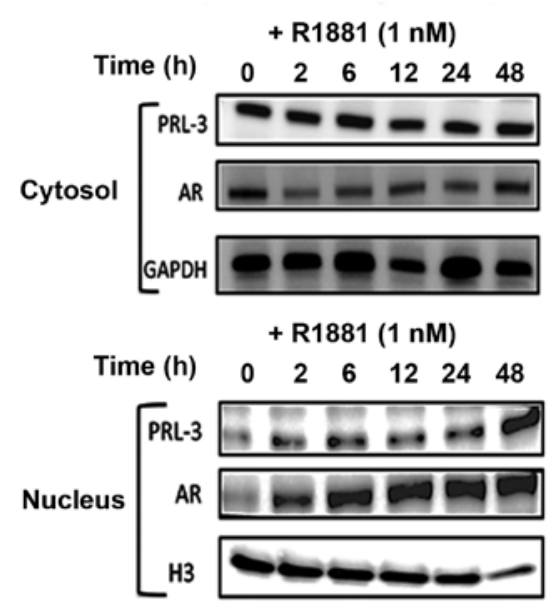

C LNCaP-SF

(hormone-independent)

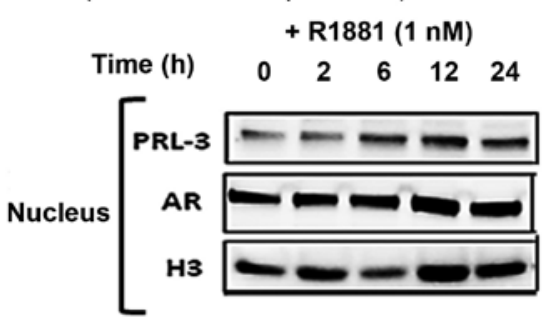

D $\underline{\mathrm{PC} 3}$

(AR-null)

$\square$ Vector

PRL-3

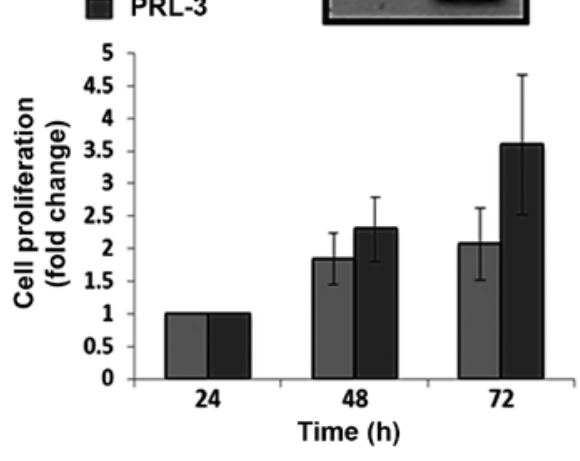

E

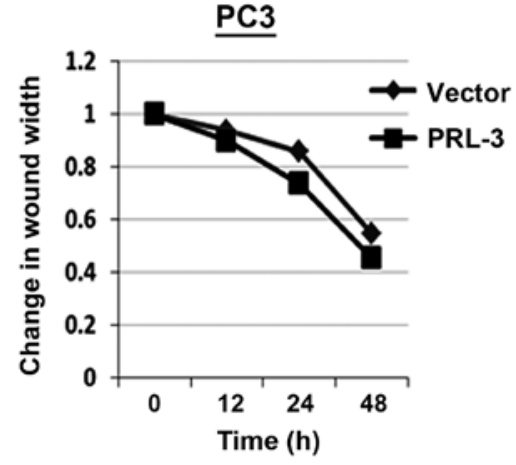

$\mathbf{F}$

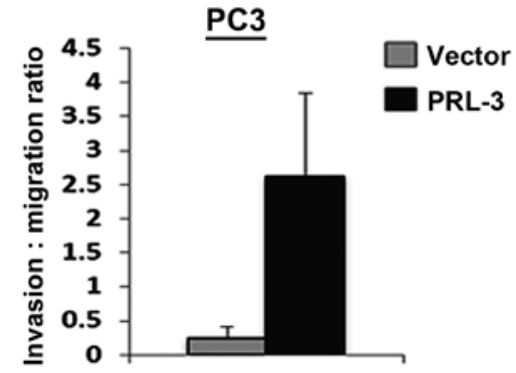

Figure 4. Phosphatase of regenerating liver-3 (PRL-3) expression and function in prostate cancer (PCa) cell lines. (A) Immunoblot analysis of PRL-3 and androgen receptor (AR) expression in PCa cell lines. (B) Immunoblot analysis of both cytosolic/membrane (top panel) and nuclear fractions (bottom panel) of PRL-3 in LNCaP cells. Both basal and R1881-stimulated AR and PRL-3 are shown at different times post-stimulation. (C) Nuclear PRL-3 levels in LNCaP-SF cells under both basal and R1881 (1 nM) stimulated conditions. Histone-3 (H3) was used as a loading control for nuclear extract. (D) Effect of PRL-3 overexpression on PC3 cell proliferation. Figure inset shows immunoblot of PRL-3 in PRL-3-vector transfected cells.-fold change in proliferation in PRL-3-vector transfected cells, as compared to control-vector transfected cells, is shown. (E) Effect of PRL-3 overexpression on migratory phenotype of PC 3 cells as measured by wound-heal assay. Change in wound width at different time-points (0-48 h) are shown in the line graphs. (F) Effect of PRL-3 overexpression on invasion of PC3 cells as measured by Boyden chamber assay. Bar graph shows the comparative analysis of invasion vs. migration in control and PRL-3-vector transfected cells. Nuclear localization of PRL-3 was androgen-regulated and coincides with AR status of PCa cells. Ectopic expression of PRL-3 confers increased proliferation and invasion potential in PC3 cells.

PRL-3 in the LNCaP cells (Fig. 4B, bottom panel). The CRPC cell line, LNCaP-SF, exhibited constitutive nuclear AR levels and R1881 stimulation only slightly increased the nuclear AR levels in these cells (Fig. 4C). This clearly indicated that PRL-3 expression correlated with the AR status of $\mathrm{PCa}$ cell lines and that PRL-3 translocated to the nucleus following R1881 stimulation. Most interestingly, similar to AR, the aggressive CRPC cells exhibited constitutive nuclear PRL-3 levels.

We also examined whether PRL-3 overexpression alters cellular functions associated with aggressive PCa. For these experiments, the AR-null and PRL-3-null cell line, PC3, was transfected with a PRL-3 expression vector and the resultant effects on cell growth, invasion and migration were measured.
Data from MTT assays revealed that, as compared to the vector controls, the PRL-3-overexpressing PC3 cells exhibited an enhanced rate of proliferation at both 48 and $72 \mathrm{~h}$ post-transfection (Fig. 4D). Almost a 2-fold increase in cell numbers was evident at $72 \mathrm{~h}$ in the PRL-3-overexpressing cells. In addition, the effects of PRL-3 overexpression on the migratory (Fig. 4E) and invasive (Fig. 4F) potential of the PC3 cells were assessed by scratch wound and Boyden chamber assays, respectively. The ectopic expression of PRL-3 did not affect the migratory behavior of the PC3 cells (Fig. 4E); however, it profoundly increased the invasive potential of these cells. As compared to the cells transfected with the control vector, the PRL-3 vectortransfected cells exhibited a 2-3-fold higher invasive potential 
Table I. Descriptive statistical analysis of total PRL3 expression.

\begin{tabular}{|c|c|c|c|c|}
\hline & $\mathrm{N}(\%)$ & Median (IQR) & $\begin{array}{c}\text { Mean } \\
\text { rank }\end{array}$ & P-value \\
\hline \multicolumn{5}{|l|}{ Disease state } \\
\hline Non-malignant & $15(14.2)$ & $0.82(0.69,0.95)$ & 22.13 & \\
\hline Malignant & $91(85.8)$ & $1.18(1.05,1.32)$ & 58.67 & $<0.0001$ \\
\hline Total & $106(100)$ & & & \\
\hline \multicolumn{5}{|l|}{ Gleason grade } \\
\hline Control & $15 \quad(15)$ & $0.82(0.69,0.95)$ & 18.5 & \\
\hline 1 & $4 \quad(4.0)$ & $1.2(0.83,1.32)$ & 48.38 & \\
\hline 2 & (8) & $1.47(1.18,1.59)$ & 73.25 & $<0.001$ \\
\hline 3 & $22 \quad(22)$ & $1.18(0.99,1.31)$ & 52.09 & $<0.01$ \\
\hline 4 & $35 \quad(35)$ & $1.25(1.09,1.54)$ & 60.76 & $<0.0001$ \\
\hline 5 & $16 \quad(16)$ & $1.15(1.02,1.26)$ & 45.03 & \\
\hline Total & $100(100)$ & & & \\
\hline \multicolumn{5}{|l|}{ Gleason score } \\
\hline Control & $15(15.3)$ & $0.82(0.69,0.95)$ & 18.3 & \\
\hline $\mathrm{GS}<6$ & $25(25.5)$ & $1.23(1.06,1.44)$ & 55.3 & $<0.01$ \\
\hline GS $3+4$ & $8 \quad(8.2)$ & $1.25(0.90,1.48)$ & 55.6 & $<0.05$ \\
\hline GS 4+3 & $5 \quad(5.1)$ & $1.09(0.93,1.21)$ & 37.6 & \\
\hline GS 8 & $13(13.3)$ & $1.55(1.25,1.68)$ & 77 & $<0.0001$ \\
\hline GS 9-10 & $32(32.6)$ & $1.16(1.05,1.28)$ & 48.75 & $<0.01$ \\
\hline Total & $98(100)$ & & & \\
\hline \multicolumn{5}{|l|}{ Tumor stage } \\
\hline Control & $15(14.7)$ & $0.82(0.69,0.95)$ & 19.3 & \\
\hline $\mathrm{T} 2$ & $74(72.5)$ & $1.23(1.09,1.36)$ & 60.1 & $<0.0001$ \\
\hline $\mathrm{T} 3$ & $6 \quad(5.9)$ & $1.21(1.02,1.49)$ & 56.92 & \\
\hline $\mathrm{T} 4$ & $7 \quad(6.9)$ & $0.81(0.77,1.20)$ & 25.1 & \\
\hline Total & $102(100)$ & & & \\
\hline
\end{tabular}

through Matrigel-coated membrane inserts (Fig. 4F). Thus, PRL-3 overexpression may play a direct role in both the proliferation and invasion of PCa cells. These findings also suggested that the androgen-stimulated nuclear localization of PRL-3 may be associated with the aggressive phenotype of PCa cell lines.

Nuclear PRL-3 is associated with high-grade tumors in patients. By the digital quantification of immunostained tumor cores (Fig. 1), we evaluated the differences in cytoplasmic and nuclear PRL-3 staining (Fig. 5). The nuclear/cytoplasmic ratios for PRL-3 (Nuc:Cyto) were digitally quantified and compared with different pathological states (Table II). The GS6 tumor cores exhibited a very sparse number of cells with nuclear PRL-3, and the more aggressive tumors, particularly the GS8and GS9-graded cores, clearly demonstrated a larger population of cells with intense nuclear PRL-3 staining (Fig. 5A). Of note, in the GS7- and GS8-graded cores, we also noted that nuclear PRL-3 was primarily localized in the central part of the nucleus. However, in the GS9-graded cores, nuclear PRL-3 was more frequently associated with the periphery of the nucleus rather than within the central regions. The analysis of both non-malignant $(n=15)$ vs. malignant cores $(n=91)$ clearly revealed that nuclear PRL-3 was positively associated with prostate adenocarcinoma $(\mathrm{U}=136.5, \mathrm{P}<0.0001)$. Importantly, the nuclear/ cytoplasmic ratio assessments demonstrated increased $(\mathrm{P}<0.05)$
Table II. Descriptive statistical analysis of nuclear PRL-3 expression.

\begin{tabular}{|c|c|c|c|c|}
\hline & $\mathrm{N}(\%)$ & Median (IQR) & $\begin{array}{c}\text { Mean } \\
\text { rank }\end{array}$ & P-value \\
\hline \multicolumn{5}{|l|}{ Disease state } \\
\hline Non-malignant & $15(14.2)$ & $0.76(0.69,0.85)$ & 17.1 & \\
\hline Malignant & $91(85.8)$ & $1.07(1.0,1.2)$ & 59.5 & $<0.0001$ \\
\hline Total & $106(100)$ & & & \\
\hline \multicolumn{5}{|l|}{ Gleason grade } \\
\hline Control & 15 (15) & $0.76(0.69,0.85)$ & 16 & \\
\hline 1 & $4(4.0)$ & $1.00(0.89,1.1)$ & 40 & \\
\hline 2 & $8 \quad(8)$ & $1.06(0.92,1.1)$ & 48.44 & \\
\hline 3 & 22 (22) & $1.01(0.97,1.11)$ & 45.6 & $<0.05$ \\
\hline 4 & $35 \quad(35)$ & $1.1(1.02,1.21)$ & 62.19 & $<0.0001$ \\
\hline 5 & $16(16)$ & $1.1(1.07,1.21)$ & 67.59 & $<0.0001$ \\
\hline Total & $100(100)$ & & & \\
\hline \multicolumn{5}{|l|}{ Gleason score } \\
\hline Control & $15(15.3)$ & $0.76(0.69,0.85)$ & 16.07 & \\
\hline $\mathrm{GS}<6$ & $25(25.5)$ & $1.23(1.06,1.44)$ & 45.2 & $<0.05$ \\
\hline GS $3+4$ & $8 \quad(8.2)$ & $1.25(0.90,1.48)$ & 50.67 & \\
\hline GS 4+3 & $5 \quad(5.1)$ & $1.09(0.93,1.21)$ & 64.9 & $<0.05$ \\
\hline GS 8 & $13(13.3)$ & $1.55(1.24,1.68)$ & 43.81 & \\
\hline GS 9-10 & $32(32.6)$ & $1.16(1.05,1.28)$ & 69.66 & $<0.0001$ \\
\hline Total & $98(100)$ & & & \\
\hline \multicolumn{5}{|l|}{ Tumor stage } \\
\hline Control & $15(14.7)$ & $0.76(0.68,0.95)$ & 16.93 & \\
\hline $\mathrm{T} 2$ & $74(72.5)$ & $1.08(1.00,1.19)$ & 59.63 & $<0.0001$ \\
\hline $\mathrm{T} 3$ & $6 \quad(5.9)$ & $0.99(0.86,1.07)$ & 37 & \\
\hline $\mathrm{T} 4$ & $7 \quad(6.9)$ & $1.07(0.92,1.4)$ & 58.44 & $<0.001$ \\
\hline Total & $102(100)$ & & & \\
\hline
\end{tabular}

nuclear PRL-3 in the highly aggressive GS7 (4+3)-graded cores compared to the less aggressive GS7 (3+4)-graded cores (Fig. 5C and Table II). Similarly, despite decreases in total PRL-3 in both the GS9- and GS10-graded cores (Fig. 3C and Table I), the number of cells containing nuclear PRL-3 was significantly $(\mathrm{P}<0.0001)$ higher in the highly aggressive tumor cores (Fig. 5C and Table II). When grouped according to tumor grade, mean rank analysis also revealed the increased nuclear accumulation of PRL-3 in the GG4- and GG5-graded cores $(\mathrm{P}<0.0001)$. Nuclear PRL-3 expression exhibited a strong association with both intermediate (int) and poorly differentiated (PD) tumor patterns, as compared to well-differentiated (WD) tumors $(\mathrm{P}<0.0001)$ where PRL-3 was primarily localized in the cytoplasm of WD tumors (GS $\leq 6)$; however, both the intermediate (GS7) and poorly-differentiated (GS >7) tumors exhibited a higher nuclear PRL3 expression (Fig. 5D). Thus, the Nuc:Cyto ratio of PRL-3 may be used to distinguish between indolent and aggressive disease.

Clinicopathological association of nuclear PRL-3 with T-stage. T-staging in the PCa specimens allows clinicians to estimate the extension of tumor burden $(27,28)$. In this study, the TMA cohort was largely composed of T2-stage tumors and not T3and T4-stage tumors, which made the statistical correlation 
A
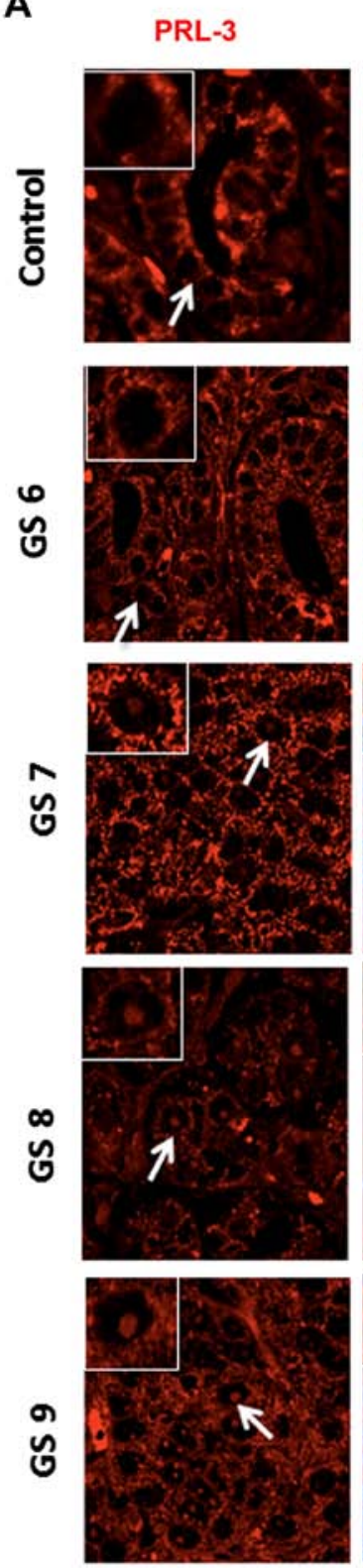

PRL-3, DAPI
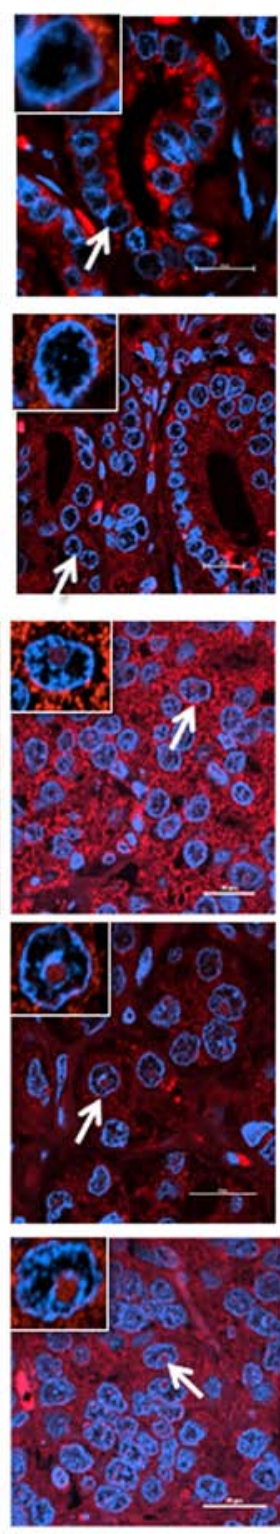

B

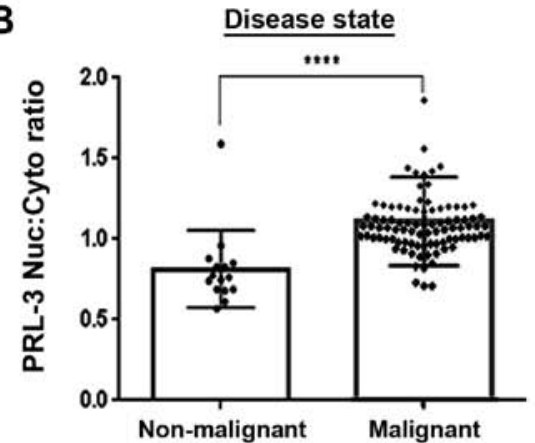

C

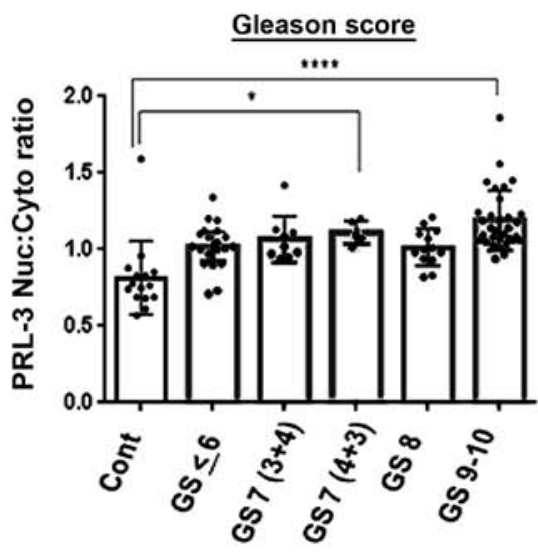

D

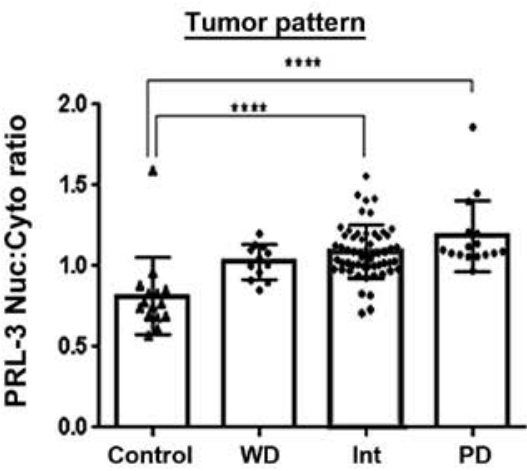

Figure 5. Nuclear phosphatase of regenerating liver-3 (PRL-3) levels in high-grade prostate tumor cores. (A) Detection of PRL-3 in the nuclei of high-grade tumor cores. White arrows indicate the area selected within the figure inset (scale bar, $20 \mu \mathrm{m}$ ). Higher magnification images show PRL-3 within nucleolar regions. (B) Quantitative evaluation of nuclear PRL-3 in non-malignant and malignant tumor cores. Nuclear localization of PRL-3 is associated with prostate adenocarcinomas. (C) PRL-3 nuclear localization is significantly associated with GS7 (4+3) cores and high-grade disease (GS9-10). (D) Nuclear PRL-3 is associated with both intermediate (int) and poorly differentiated (PD) tumors, but not with well-differentiated (WD) tumor cores $(\mathrm{P}<0.0001)$. Error bars represent interquartile ranges, $\mathrm{a}=0.05\left({ }^{*} \mathrm{P}<0.05 ;{ }^{* *} \mathrm{P}<0.01 ;{ }^{* * *} \mathrm{P}<0.001\right.$; and $\left.{ }^{* * * *} \mathrm{P}<0.0001\right)$. PRL-3 localizes to the nucleus in high-grade prostate tumor cores.

more difficult. However, a trend that distinguishes the aggressive phenotype was clearly documented (Fig. 6). A significant difference in PRL-3 protein levels between non-malignant areas and the $\mathrm{T} 2$ cores was observed $(\mathrm{P}<0.0001)$. Although the T2-stage cores exhibited detectable PRL-3 expression, much stronger expression was observed in specific areas within the T3- and T4-stage tumor cores (Fig. 6A). Of note, these PRL-3-overexpressed areas were also found to contain higher levels of nuclear PRL-3 expression, and this phenomenon was particularly striking in the T4-stage tumor cores. Furthermore, as compared to the T2-stage cores, total PRL-3 expression was decreased $(\mathrm{P}<0.05)$ in the T4-stage cores (Fig. 6B). When comparing cores stratified by their primary tumor staging, distinct differences in both global and nuclear PRL-3 expressions were also documented. The T2-stage cores consistently exhibited a higher total PRL-3 expression as compared to the control sections (Fig. 6B and Table I). In addition, the nuclear:cytoplasmic mean ranks were significantly $(\mathrm{P}<0.0001)$ higher in both the $\mathrm{T} 2$ - and T4-stage $(\mathrm{P}<0.01)$ cores, as compared to the control sections (Fig. 6C and Table II). Thus, nuclear PRL-3 is a reliable biomarker of clinically relevant disease and correlate with TNM classifications.

Nuclear PRL-3 levels correlate with Ki67 expression in tumor sections. Our in vitro experiments on PRL-3-overexpressing PCa cells indicated its role in increasing cell proliferation (Fig. 4). Therefore, in prostate tumor sections, we wished to determine whether tumor cores with a high PRL-3 expression and increased nuclear PRL-3 levels are similarly associated with the prolifera- 
A
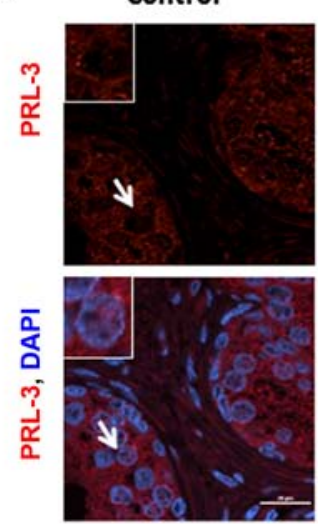

B

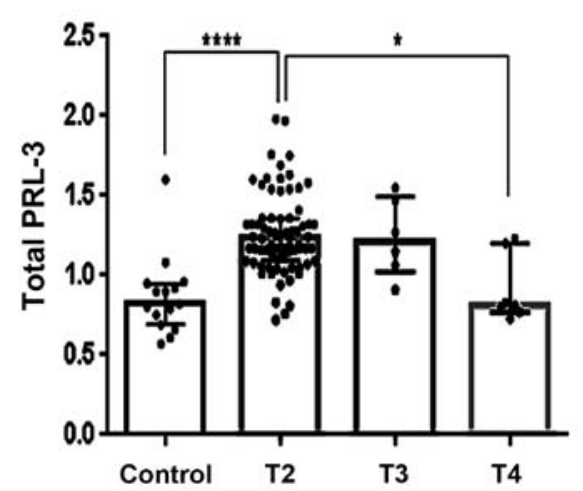

T3
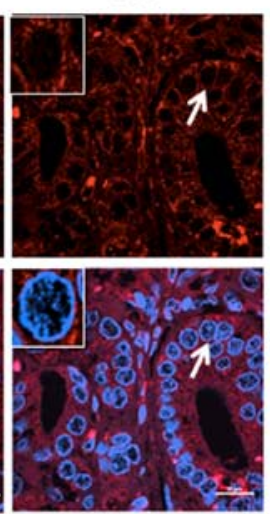

C

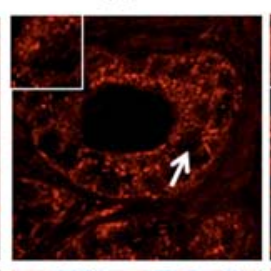

T4
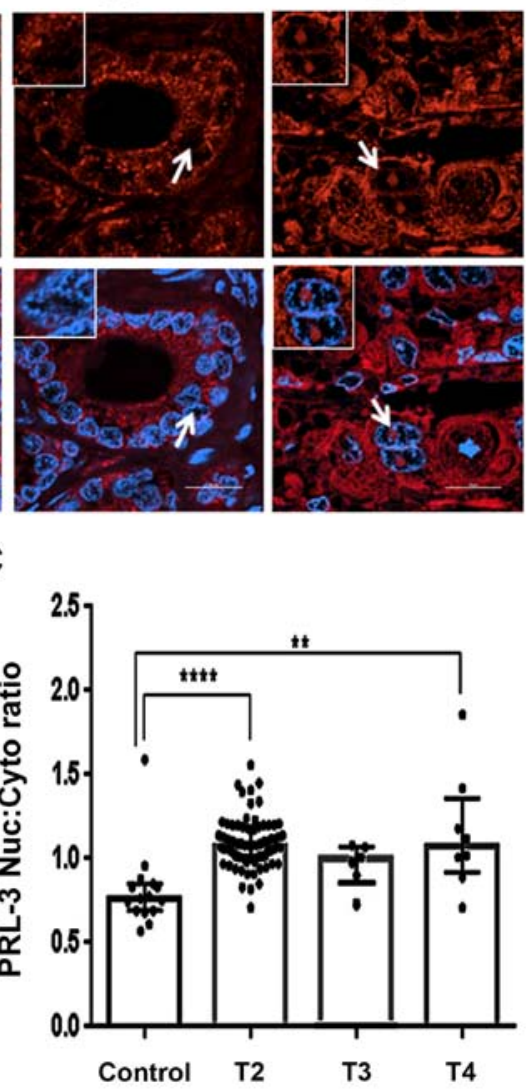

Figure 6. Clinicopathological significance of nuclear phosphatase of regenerating liver-3 (PRL-3). (A) PRL-3 was more frequently detected in the nuclei of T4-stage tumor cores. White arrows indicate the area selected within the figure inset (scale bar, $20 \mu \mathrm{m}$ ). Higher magnification images show PRL-3 within nucleolar regions. (B) Total PRL-3 overexpression was associated more with the T2- and T3-stage tumors. (C) Nuclear PRL-3 localization correlated with clinically advanced tumor progression (T4-stage). Error bars represent interquartile ranges, a $=0.05\left({ }^{*} \mathrm{P}<0.05 ;{ }^{* *} \mathrm{P}<0.01{ }^{* * *} \mathrm{P}<0.001\right.$; and $\left.{ }^{* * * *} \mathrm{P}<0.0001\right)$. Nuclear $\mathrm{PRL}-3$ was associated with advanced clinical staging.

A

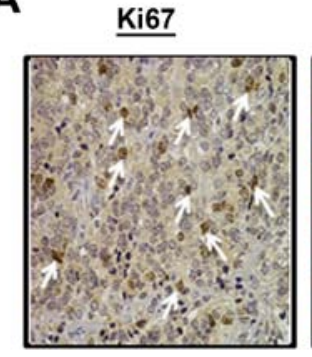

B

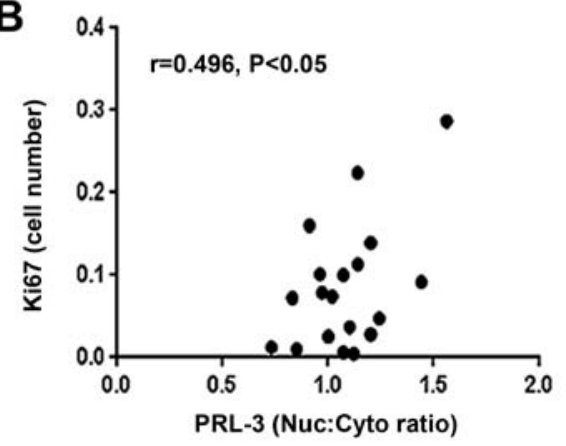

Figure 7. Correlation between nuclear phosphatase of regenerating liver-3 (PRL-3) and Ki67 levels. (A) A representative image of tumor core stained with Ki67 (left panel) and PRL-3 (right panel). (B) Pearson's r correlation analysis of nuclear/cytoplasmic (Nuc:Cyto) ratio of PRL-3 and Ki67 staining intensity in tumor specimen. Ki67 staining positively correlated with nuclear PRL-3 $(\mathrm{P}<0.05)$. tion marker, Ki67 (Fig. 7). Tumor cores were immunostained for both Ki67 and PRL-3, followed by DIA and comparison of the proliferative index. Pearson's $r$ correlation analysis indicated that tumor sections with a higher nuclear PRL-3 expression were positively associated with increased Ki67-labeled cells ( $\mathrm{r}=0.496$, $\mathrm{P}<0.05$ ). Similar to our findings of the total and Nuc:Cyto levels of PRL-3 in the GS-, GG- and TNM-stratified TMA cores, it was suggested that nuclear PRL-3 was directly associated with aggressively increasing areas of the prostate tumors.

\section{Discussion}

An increased PRL-3 expression is associated with a poor prognosis of several solid tumors, e.g., breast $(12,29)$, colorectal $(13,26)$, gastric $(30,31)$ and ovarian cancer (32). However, the potential for PRL-3 as a biomarker for PCa has not yet been thoroughly evaluated, at least to the best of our knowledge. Through integrative genomic profiling of the Oncomine database provided in 4 different reports (21-24), $P R L-3$ gene expression was found to be significantly associated with PCa (Fig. 2). An increased PRL-3 expression was associated with a poor clinical outcome, as demonstrated by its mRNA levels in the 75th percentile of genes overexpressed in patients with a higher mortality rate. Although previous studies have suggested that PRL-3 may play a major role in the aggressive and metastatic phenotype of tumors $(33,34)$, only one previous study assessed PRL-3 protein 
in PCa patient tumor samples (35). Also, the present study, to the best of our knowedge, illustrates for the first time that the nuclear localization of PRL-3 may be an indicator of aggressive tumors.

The study by Vandsemb et al demonstrated that both PRL-3 mRNA and protein levels were higher in primary prostate tumors and in the corresponding lymph node metastases (35). Furthermore, in vitro assays suggested that PRL-3 promoted both the growth and migration of PCa cells. However, the subcellular localization of PRL-3 and its implications in regulating PCa cell function were not evaluated in this previous study (35). The current study used a large number of prostate tumor cores and clearly provided evidence that PRL-3 protein levels were significantly higher in tumor nodes as compared to the normal prostate stroma (Fig. 3 and Table I). In addition, our findings also implicated that nuclear PRL-3 may be positively associated with high-grade tumors (Fig. 5 and Table II). Importantly, a differential subcellular localization of PRL-3 was documented in the two subtypes of GS7-graded tumors, where the 3+4 tumor cores (less aggressive) exhibited lower nuclear PRL-3 expression than the $4+3$ tumor cores (more aggressive). Clinicopathological association analysis also revealed that PRL-3 overexpression was associated with early clinical disease and nuclear PRL-3 was directly linked to the advanced clinical stages (T4-stage) (Fig. 6). Therefore, both the total and nuclear PRL-3 protein levels may help to identify aggressive tumor phenotypes.

Recent studies have suggested a nuclear regulatory function of PRL-3 in cancer cells $(36,37)$. Furthermore, Fagerli et al implicated a cell cycle-dependent nuclear/cytoplasmic shuttling of PRL-3 in human myeloma cells (38). These findings implicated differential functions of this phosphatase in both the cytoplasmic and nuclear compartments. Preliminary in vitro experiments in our laboratory, using the androgen-dependent PCa line (LNCaP) clearly revealed that stimulation with the AR agonist, R1881, rapidly increased the nuclear translocation of PRL-3 (Fig. 4B). Furthermore, in the LNCaP-SF cells, a CRPC subline of $\mathrm{LNCaP}$, we observed constitutive nuclear localization of both AR and PRL-3 (Fig. 4C). These data in the PCa cell lines are in concordance with our observations in prostate tumor cores, particularly those with a hormone-refractory (CRPC) phenotype. Of note, Vandsemb et al demonstrated that the inhibition of PRL-3 reduced migration, growth arrest and the apoptosis of PCa cell lines (35), clearly implying a direct role for PRL-3 in aggressive PCa cells. Our preliminary findings suggested that PRL-3 may be co-chaperoned with AR following androgen (R1881) stimulation, and may be critical in several tumor inductive pathways. However, further studies are required in order to evaluate the functional association between $\mathrm{AR}$ and PRL-3 in both the cytoplasm and in the nucleus of PCa cells.

Of note, the accumulation of PRL-3 appeared within the central nuclear regions (Figs. 5 and 6). The nucleolar accumulation of the tumor suppressor, p53 has previously been demonstrated (36). The promotion of p53 degradation by mouse double minute 2 homolog (MDM2) is also known to occur within the nucleoli (37). Indeed, Basak et al, had previously documented that PRL-3 was a p53 target (9) and Min et al, documented that PRL-3 suppressed p53 levels by regulating MDM2 function (10). Therefore, our findings on the AR signaling-mediated nuclear accumulation of PRL-3 implicate its novel role in regulating the mitogenic functions of p53. Our preliminary findings with Ki67 immunostaining of tumor cores further corroborated that nuclear
PRL-3 may indeed be associated with aggressively growing PCa cells (Fig. 7). Regions of high nuclear PRL-3 positively correlated with increased Ki67 staining $(r=0.496, \mathrm{P}<0.05)$. Therefore, it would be interesting to determine whether these same cells also have increased nuclear AR levels.

Ultimately, the combined utility of nuclear AR and PRL-3 as biomarkers of PCa progression may be useful in accurately identifying aggressive tumors $(9,14,30,39)$. Indeed, the lack of biomarkers of PCa progression, i.e., from indolent (GS7, 3+4) to aggressive (GS7, 4+3) disease, has been a major obstacle in deciding treatment guidelines (40). Although both PCA3 (3) and TMPRSS2-ERG $(4,5)$ are overexpressed in prostate tumors, their use alone may not be sufficient in distinguishing between indolent vs. aggressive disease in all patients. Therefore, other functional biomarkers, such as PRL-3 may be employed at the biopsy level to decide whether to follow with active surveillance or prescribe aggressive therapy in patients (41).

In conclusion, our preliminary findings on a large number of tumor cores suggest that PRL-3 may be a reliable biomarker for early $\mathrm{PCa}$ detection and may provide a predictive indicator of tumor progression. In this respect, our protocol of computer aided image analysis (DIA) of immunostained tumor sections (Fig. 1) to measure both the total expression and subcellular localization of PRL-3, may offer significant advances in recognizing the aggressive PCa cells by digital pathology (42). However, although we present evidence that both total and nuclear PRL-3 can predict disease progression, further prospective large cohort studies are warranted to unequivocally determine whether its expression and/or subcellular localization is associated with poor clinical outcomes. In addition, diverse functions of this phosphatase in different subcellular locations may provide insight into its mechanism/s and implicate novel therapeutic strategies. In this respect, our novel observations that androgen (R1881) stimulation increases nuclear PRL-3 levels implicates the potential of suppressing AR-signaling to downregulate the deleterious functions of nuclear PRL-3. Indeed, our recent findings showed that the phytochemical agent, Sulforaphane (43) as well as the potent pharmaceutical drug, Bardoxolone-methyl (44) can decrease AR expression. Therefore, studies to suppress PRL-3 levels and decrease the metastatic potential of PCa cells may be of significant translational value.

\section{Acknowledgements}

The present study was supported by funds from the Louisiana Cancer Research Consortium (LCRC), Tulane Biomedical Sciences (BMS) and Southern Regional Education Board (SREB).

\section{References}

1. Howlader N, Noone AM, Krapcho M, Garshell J, Miller D, Altekruse SF, Kosary CL, Yu M, Ruhl J, Tatalovich Z, Mariotto A, Lewis DR, Chen HS, Feuer EJ and Cronin KA (eds): SEER Cancer Statistics Review 1975-2011. National Cancer Institute, Bethesda, MD, https://seer.cancer.gov/archive/csr/1975_2011/. Accessed December 17, 2014.

2. Hayes JH and Barry MJ: Screening for prostate cancer with the prostate-specific antigen test: A review of current evidence. JAMA 311: 1143-1149, 2014.

3. Bussemakers MJ, van Bokhoven A, Verhaegh GW, Smit FP, Karthaus HF, Schalken JA, Debruyne FM, Ru N and Isaacs WB: DD3: A new prostate-specific gene, highly overexpressed in prostate cancer. Cancer Res 59: 5975-5979, 1999. 
4. Tomlins SA, Laxman B, Varambally S, Cao X, Yu J, Helgeson BE, Cao Q, Prensner JR, Rubin MA, Shah RB, et al: Role of the TMPRSS2-ERG gene fusion in prostate cancer. Neoplasia 10: $177-188,2008$

5. Font-Tello A, Juanpere N, de Muga S, Lorenzo M, Lorente JA, Fumado L, Serrano L, Serrano S, Lloreta J and Hernández S: Association of ERG and TMPRSS2-ERG with grade, stage, and prognosis of prostate cancer is dependent on their expression levels. Prostate 75: 1216-1226, 2015.

6. Penney KL, Pettersson A, Shui IM, Graff RE, Kraft P, Lis RT, Sesso HD, Loda M and Mucci LA: Association of prostate cancer risk variants with TMPRSS2:ERG status: Evidence for distinct molecular subtypes. Cancer Epidemiol Biomarkers Prev 25: 745-749, 2016

7. Al-Aidaroos AQ and Zeng Q: PRL-3 phosphatase and cancer metastasis. J Cell Biochem 111: 1087-1098, 2010.

8. Liu Y, Zhou J, Chen J, Gao W, Le Y, Ding Y and Li J: PRL-3 promotes epithelial mesenchymal transition by regulating cadherin directly. Cancer Biol Ther 8: 1352-1359, 2009.

9. Basak S, Jacobs SB, Krieg AJ, Pathak N, Zeng Q, Kaldis P, Giaccia AJ and Attardi LD: The metastasis-associated gene Prl-3 is a p53 target involved in cell-cycle regulation. Mol Cell 30: 303-314, 2008

10. Min SH, Kim DM, Heo YS, Kim HM, Kim IC and Yoo OJ: Downregulation of $\mathrm{p} 53$ by phosphatase of regenerating liver 3 is mediated by MDM2 and PIRH2. Life Sci 86: 66-72, 2010.

11. Wang H, Quah SY, Dong JM, Manser E, Tang JP and Zeng Q PRL-3 down-regulates PTEN expression and signals through PI3K to promote epithelial-mesenchymal transition. Cancer Res 67: 2922-2926, 2007

12. den Hollander P, Rawls K, Tsimelzon A, Shepherd J, Mazumdar A Hill J, Fuqua SA, Chang JC, Osborne CK, Hilsenbeck SG, et al Phosphatase PTP4A3 promotes triple-negative breast cancer growth and predicts poor patient survival. Cancer Res 76 1942-1953, 2016

13. Xu H, Zeng Y, Liu L, Gao Q, Jin S, Lan Q, Lai W, Luo X, Wu H, Huang Y, et al: PRL-3 improves colorectal cancer cell proliferation and invasion through IL-8 mediated glycolysis metabolism. Int J Oncol 51: 1271-1279, 2017.

14. Jiang Y, Liu XQ, Rajput A, Geng L, Ongchin M,Zeng Q, Taylor GS and Wang J: Phosphatase PRL-3 is a direct regulatory target of TGFbeta in colon cancer metastasis. Cancer Res 71: 234-244, 2011

15. Iwasa Y, Mizokami A, Miwa S, Koshida K and Namiki M: Establishment and characterization of androgen-independent human prostate cancer cell lines, LN-REC4 and LNCaP-SF, from LNCaP. Int J Urol 14: 233-239, 2007.

16. van Bokhoven A, Varella-Garcia M, Korch C, Johannes WU, Smith EE, Miller HL, Nordeen SK, Miller GJ and Lucia MS: Molecular characterization of human prostate carcinoma cell lines. Prostate 57: 205-225, 2003.

17. Noursadeghi M, Tsang J, Haustein T, Miller RF, Chain BM and Katz DR: Quantitative imaging assay for NF-kappaB nuclear translocation in primary human macrophages. J Immunol Methods 329: 194-200, 2008

18. Rubin MA, Mucci NR, Figurski J, Fecko A, Pienta KJ and Day ML: E-cadherin expression in prostate cancer: A broad survey using high-density tissue microarray technology. Hum Pathol 32: 690-697, 2001

19. McMenamin ME, Soung P, Perera S, Kaplan I, Loda M and Sellers WR: Loss of PTEN expression in paraffin-embedded primary prostate cancer correlates with high Gleason score and advanced stage. Cancer Res 59: 4291-4296, 1999.

20. Rhodes DR, Yu J, Shanker K, Deshpande N, Varambally R, Ghosh D, Barrette T, Pandey A and Chinnaiyan AM: ONCOMINE: A cancer microarray database and integrated data-mining platform. Neoplasia 6: 1-6, 2004

21. Liu P, Ramachandran S, Ali Seyed M, Scharer CD, Laycock N, Dalton WB, Williams H, Karanam S, Datta MW, Jaye DL, et al: Sex-determining region $\mathrm{Y}$ box 4 is a transforming oncogene in human prostate cancer cells. Cancer Res 66: 4011-4019, 2006.

22. Wallace TA, Prueitt RL, Yi M, Howe TM, Gillespie JW Yfantis HG, Stephens RM, Caporaso NE, Loffredo CA and Ambs S: Tumor immunobiological differences in prostate cancer between African-American and European-American men. Cancer Res 68: 927-936, 2008

23. Taylor BS, Schultz N, Hieronymus H, Gopalan A, Xiao Y, Carver BS Arora VK, Kaushik P, Cerami E, Reva B, et al: Integrative genomic profiling of human prostate cancer. Cancer Cell 18: 11-22, 2010.

24. Grasso CS, Wu YM, Robinson DR, Cao X, Dhanasekaran SM, Khan AP, Quist MJ, Jing X, Lonigro RJ, Brenner JC, et al: The mutational landscape of lethal castration-resistant prostate cancer. Nature 487: 239-243, 2012.
25. Chong PS, Zhou J, Cheong LL, Liu SC, Qian J, Guo T, Sze SK, Zeng Q and Chng WJ: LEO1 is regulated by PRL-3 and mediates its oncogenic properties in acute myelogenous leukemia. Cancer Res 74: 3043-3053, 2014.

26. Liu Y, Zheng P, Liu Y, Ji T, Liu X, Yao S, Cheng X, Li Y, Chen L, Xiao Z, et al: An epigenetic role for PRL-3 as a regulator of H3K9 methylation in colorectal cancer. Gut 62: 571-581, 2013.

27. van Oort IM, Witjes JA, Kok DE, Kiemeney LA and HulsbergenVan De Kaa CA: The prognostic role of the pathological T2 subclassification for prostate cancer in the 2002 Tumour-NodesMetastasis staging system. BJU Int 102: 438-441, 2008.

28. Caso JR, Tsivian M, Mouraviev V, Polascik TJ and Moul JW: Pathological T2 sub-divisions as a prognostic factor in the biochemical recurrence of prostate cancer. BJU Int 106: $1623-1627,2010$

29. Wang L, Peng L, Dong B, Kong L, Meng L, Yan L, Xie Y and Shou C: Overexpression of phosphatase of regenerating liver-3 in breast cancer: Association with a poor clinical outcome. Ann Oncol 17: 1517-1522, 2006.

30. Ooki A, Yamashita K, Kikuchi S, Sakuramoto S, Katada N, Waraya M, Kawamata $\mathrm{H}$, Nishimiya $\mathrm{H}$, Nakamura $\mathrm{K}$ and Watanabe M: Therapeutic potential of PRL-3 targeting and clinical significance of PRL-3 genomic amplification in gastric cancer. BMC Cancer 11: 122, 2011.

31. Xing X, Lian S, Hu Y, Li Z, Zhang L, Wen X, Du H, Jia Y, Zheng Z, Meng L, et al: Phosphatase of regenerating liver-3 (PRL-3) is associated with metastasis and poor prognosis in gastric carcinoma. J Transl Med 11: 309, 2013.

32. Polato F, Codegoni A, Fruscio R, Perego P, Mangioni C, Saha S, Bardelli A and Broggini M: PRL-3 phosphatase is implicated in ovarian cancer growth. Clin Cancer Res 11: 6835-6839, 2005

33. Liang F, Liang J, Wang WQ, Sun JP, Udho E and Zhang ZY: PRL3 promotes cell invasion and proliferation by down-regulation of Csk leading to Src activation. J Biol Chem 282: 5413-5419, 2007.

34. Ming J, Liu N, Gu Y, Qiu X and Wang EH: PRL-3 facilitates angiogenesis and metastasis by increasing ERK phosphorylation and up-regulating the levels and activities of Rho-A/C in lung cancer. Pathology 41: 118-126, 2009.

35. Vandsemb EN, Bertilsson H, Abdollahi P, Størkersen $\varnothing$, Våtsveen TK, Rye MB, Rø TB, Børset M and Slørdahl TS: Phosphatase of regenerating liver 3 (PRL-3) is overexpressed in human prostate cancer tissue and promotes growth and migration. J Transl Med 14: 71, 2016.

36. Burk U, Selter H, Zwergel T, Wullich B, Montenarh $M$ and Unteregger G: Different subnuclear localization of wild-type and mutant p53 in human prostate-cancer cells. Int J Oncol 7: $1355-1360,1995$.

37. Vlatković N, Boyd MT and Rubbi CP: Nucleolar control of p53: A cellular Achilles' heel and a target for cancer therapy. Cell Mol Life Sci 71: 771-791, 2014.

38. Fagerli UM, Holt RU, Holien T, Vaatsveen TK, Zhan F, Egeberg KW, Barlogie B, Waage A, Aarset H, Dai HY, et al: Overexpression and involvement in migration by the metastasisassociated phosphatase PRL-3 in human myeloma cells. Blood 111: 806-815, 2008.

39. Hein N, Hannan KM, George AJ, Sanij E and Hannan RD: The nucleolus: An emerging target for cancer therapy. Trends Mol Med 19: 643-654, 2013.

40. Romero Otero J, Garcia Gomez B, Campos Juanatey F and Touijer KA: Prostate cancer biomarkers: An update. Urol Oncol 32: 252-260, 2014.

41. Donovan MJ and Cordon-Cardo C: Predicting high-risk disease using tissue biomarkers. Curr Opin Urol 23: 245-251, 2013.

42. Stålhammar G, Fuentes Martinez N, Lippert M, Tobin NP, Mølholm I, Kis L, Rosin G, Rantalainen M, Pedersen L, Bergh J, et al: Digital image analysis outperforms manual biomarker assessment in breast cancer. Mod Pathol 29: 318-329, 2016.

43. Khurana N, Talwar S, Chandra PK, Sharma P, Abdel-Mageed AB, Mondal D and Sikka SC: Sulforaphane increases the efficacy of anti-androgens by rapidly decreasing androgen receptor levels in prostate cancer cells. Int J Oncol 49: 1609-1619, 2016.

44. Khurana N, Kim H, Chandra PK, Talwar S, Sharma P, AbdelMageed AB, Sikka SC and Mondal D: Multimodal actions of the phytochemical sulforaphane suppress both AR and AR-V7 in 22Rv1 cells: Advocating a potent pharmaceutical combination against castration-resistant prostate cancer. Oncol Rep 38: 2774-2786, 2017.

This work is licensed under a Creative Commons

Attribution-NonCommercial-NoDerivatives 4.0 International (CC BY-NC-ND 4.0) License. 